\title{
ACUMULAÇÃO DE METAIS PESADOS E ALTERAÇÃO DAS PROPRIEDADES FÍSICAS E QUÍMICAS DE AREIAS DE DUNAS LITORÂNEAS
}

\author{
ACCUMULATION OF HEAVY METALS AND ALTERATIONS OF THE PHYSICAL AND \\ CHEMICAL PROPERTIES OF THE LITORAL DUNES
}

\author{
Maria Manuela Malhado Simões RIBEIRO ${ }^{1}$, Malva Andrea MANCUSO ${ }^{2}$, Celeste R. \\ Ramalho JORGE ${ }^{3}$, Jorge Luis MARTINEZ ${ }^{4}$, João Ferro PELICA ${ }^{1}$, Maria Fernanda \\ PESSOA $^{1}$, Fernando Henrique REBOREDO ${ }^{1}$ \\ ${ }^{1}$ Geobiotec e Departamento de Ciências da Terra da Faculdade de Ciências e Tecnologia, Universidade Nova de Lisboa (UNL), \\ Câmpus de Caparica, Portugal, Email:mmsr@fct.unl.pt; mfgp@fct.unl.pt; fhr@fct.unl.pt; j.pelica@campus.fct.unl.pt \\ ${ }^{2}$ Departamento de Engenharia e Tecnologia Ambiental da Universidade Federal de Santa Maria (UFSM), Rio Grande do Sul, Brasil. \\ Email: malvamancuso@ufsm.br \\ ${ }^{3}$ Núcleo de Assessoria ao Conselho Diretivo do Laboratório Nacional de Engenharia Civil (LNEC), Lisboa. Email: cjorge@lnec.pt \\ ${ }^{4}$ CSIRO Land and Water, Brisbane. Austrália. Email: jorge.martinez@csiro.au

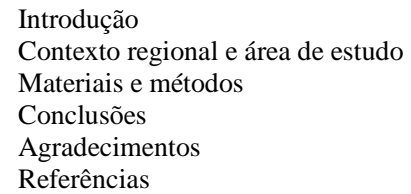

RESUMO - Nos dois últimos séculos, na orla costeira de Portugal, generalizou-se a prática agrícola em areias de duna com a aplicação de agroquímicos, sem controle técnico, de onde resultaram alterações da composição físico-química e acumulação de metais pesados nas areias. Com o objetivo de avaliar os efeitos do manejo agrícola foram coletadas e caracterizadas, do ponto de vista físico e químico, amostras da duna, entre os $0,0 \mathrm{~cm}$ e os $20 \mathrm{~cm}$ de profundidade, com e sem prática agrícola. Foi determinada, por ensaio de peneiramento, a fração fina (partículas com diâmetro inferior a 0,074 mm) e pelo método MAB - Peróxido, a composição em matéria orgânica. Foi estimada a umidade das amostras e determinado, pelo método eletroquímico, o pH, a condutividade elétrica e o potencial de oxirredução. A composição química foi analisada por fluorescência de raios X. Verificou-se que o manejo agrícola das areias de duna resultou no aumento da fração fina, da matéria orgânica, da umidade, da condutividade elétrica e do potencial de oxirredução. $\mathrm{O}$ pH diminuiu, de básico para valores próximos de neutro, aumentando o risco de acumulação e mobilização de Fe, Mn, Cu, Zn, Pb, As, Zr, Th, Rb, Cr, V, Ni, Hg, Co e U.

Palavras-chave: Areias de duna; manejo agrícola; caracterização física e química; acúmulo de metais pesados.

\begin{abstract}
During past two centuries, dunes Portuguese coastline is being used for agricultural practices with intensive use of agrochemicals and deficient technical inspection. These uses have been changing the texture and the physical and chemical composition of the sands with increased effects on the heavy metals accumulation. In order to evaluate the changes, samples of dunes, with and without agricultural uses, were collected and analyzed the chemical and physical parameters. Sieve shakers were used to determine the granulometry and the fine fraction (particles sizes with a diameter less than $0.074 \mathrm{~mm}$ ); MAB-Peroxide method was used to evaluate the organic matter content. Following electrochemical method it was measured humidity, $\mathrm{pH}$, electrical conductivity and oxidation-reduction. Mineral composition was analyzed by Portable X Ray fluorescence. This study shows an increase trend from natural dune to the agricultural land in the fine particles sizes, organic matter content, humidity, electrical conductivity and oxidation-reduction; $\mathrm{pH}$ decreased from basic conditions to an approximately neutral value, thus increasing the risk of metals mobility. A general accumulation of metals in the sand dunes with a special increase in the total concentration of Fe, Mn, $\mathrm{Cu}, \mathrm{Zn}, \mathrm{Pb}, \mathrm{As}, \mathrm{Zr}, \mathrm{Th}, \mathrm{Rb}, \mathrm{Cr}, \mathrm{V}, \mathrm{Ni}, \mathrm{Hg}$, Co and U was detected.
\end{abstract}

Keywords: Sand dune; agricultural use; physical and chemical characterization; heavy metals accumulation.

\section{INTRODUÇÃO}

Na orla costeira atlântica de Portugal a crescente fixação humana nos últimos dois séculos tem motivado a ocupação das dunas e a sua adaptação para a prática agrícola. Esta atividade ocorre há pelo menos 200 anos de forma rotativa e continuada para cultivo de produtos hortícolas. A composição arenosa das dunas permite boa absorção, drenagem de águas pluviais e percolação da infiltração. A perfuração fácil de poços cacimba para captação de água subterrânea de aquíferos livres superficiais favorece o manejo agrícola.
Segundo Eça, em 1939, as dunas suportavam uma agricultura incipiente, sendo descrita a região como "terras de areia, pobres e de fertilidade quase nula”. O uso agrícola foi possível mediante a aplicação de aditivos orgânicos de restos de pescado não consumido, e, mais tarde, com o advento da indústria química no século XX, da aplicação de aditivos inorgânicos quimicamente manufaturados. Esta prática é hoje em dia acompanhada da adição de agrotóxicos (herbicidas e pesticidas) para controle de pragas. 
Por razões econômicas os aditivos químicos, na maior parte dos casos, não são suficientemente purificados podendo conter impurezas tais como metais pesados (Zovko \& Romic, 2011; Wuana \& Okieimen, 2011; Bahrampoor, 2012). Segundo alguns autores o acúmulo de metais pesados em terrenos agrícolas resulta do uso repetido e excessivo de fertilizantes, pesticidas e resíduos orgânicos (Tiller, 1989; Alloway, 1990, Blume \& Brümmer, 1991; Gimeno-Garcia et al., 1996; Ramalho et al., 2000; Järup 2003; Wang et al., 2005; Gupta et al., 2011; Kabata-Pendias, 2011; Rahman et al., 2012; SCU, 2013). Entre esses, por serem os mais tóxicos, destacam-se os íons de $\mathrm{Pb}$, o Cd, o As, o Cr, o Hg, o Zn, o Ni, o Co e o Mo (Bašić et al., 2001; IINERT, 2006; Misa, 2010).

Estudos realizados em zonas costeiras alertam para a adoção de práticas agrícolas desajustadas às condições naturais dos terrenos e para a aplicação de elevadas quantidades de agroquímicos, por causarem forte impacto ambiental e a contaminação dos ecossistemas (Jorge et al., 2012; Sowana et al., 2011; Yuan et al., 2014; Wang et al., 2014).
Nas Terras da Costa (Caparica, Portugal) a ocupação agrícola das dunas ocorreu no final do século XVIII quando, no início do povoado, os pescadores se fixaram na região das dunas e pós-dunas (Blanes, 2003). A atividade agrícola surgiu como complemento à atividade pesqueira, porque nem sempre as condições do mar permitiam a saída dos barcos para a faina. Atualmente, a agricultura é praticada de modo continuado em parcelas inferiores a 1 ha, situadas ao longo da planície litorânea. O alargamento da faixa agrícola ocorreu no decurso de mais de dois séculos e tornou o local um importante produtor hortícola a nível nacional (Blanes, 2003). Hoje em dia a região é mais conhecida pela atividade pesqueira e pelo potencial turístico. Em 1984, grande parte da área agrícola ficou inserida na paisagem protegida da Arriba Fóssil da Costa de Caparica de acordo com o Decreto-Lei n. ${ }^{\circ}$ 168/84 (legislação portuguesa).

O presente estudo teve por objetivo estudar as alterações sofridas na composição física e química das areias que compõem as dunas das Terras da Costa de Caparica e avaliar o efeito do manejo agrícola no acúmulo de metais pesados.

\section{CONTEXTO REGIONAL E ÁREA DE ESTUDO}

O estudo foi desenvolvido na região designada por Terras da Costa, situada no concelho de Almada e no distrito de Setúbal, Portugal. Compreende uma faixa alongada de terreno com aproximadamente 220 ha de área, que forma o cordão de dunas situado na zona costeira até à cota de $5 \mathrm{~m}$, entre o Oceano Atlântico e a falésia natural (Arriba Fóssil). É constituída por areias finas quartzosas do Quaternário assentes sobre os depósitos argilomargosos do Miocénico, que formam a planície de abrasão marinha (Figura 1). Sua formação ocorreu após uma pequena glaciação no final do século $\mathrm{XV}$ que, com a subida do nível do mar, fomentou o assoreamento das barras e a formação de bancos de areia. Com o terremoto de 1755, que abalou Portugal e especialmente a cidade de Lisboa, ocorreu a elevação e a estabilização da planície litorânea, onde se instalaram as praias, a frente das dunas e a área agrícola das Terras da Costa (Santos, 2010).

Do ponto de vista climático na região beneficia-se da influência atlântica e da proteção da falésia do litoral conformando um clima marítimo de transição, de tipo mediterrâneo, caracterizado por possuir temperaturas amenas, raras geadas, precipitação média e ventos fortes a moderados (Santos, 2001). A temperatura média anual da região é de $16,9{ }^{\circ} \mathrm{C}$ e a precipitação média anual de 730 $\mathrm{mm}$, com maior incidência nos meses de outono e inverno, oscilando entre $90 \mathrm{~mm} / \mathrm{mês}$ e 120 $\mathrm{mm} / \mathrm{mês}$, e escassa nos meses de verão, variando entre $2 \mathrm{~mm} / \mathrm{mês}$ e $20 \mathrm{~mm} / \mathrm{mês}$ (Martinez, 2010). No concelho de Almada a recarga subterrânea resulta da infiltração de águas pluviométricas, tendo sido estimada pelo método do balanço hídrico sequencial diário ao nível do solo, em $11 \%$ do total precipitado durante o período de 1981 a 2011 (Caria et al., 2013).

De acordo com Martinez (2010), a irrigação na área agrícola é realizada com água subterrânea extraída de poços cacimba, a profundidades inferiores a $8 \mathrm{~m}$, que apresentam condutividades elétricas entre $388 \mu \mathrm{S} \mathrm{cm} \mathrm{cm}^{-1}$ e $6260 \mu \mathrm{S} \mathrm{cm}{ }^{-1}$. O autor destaca que na composição físico-química dessa água foi 
observado o enriquecimento de nitratos (de 1,2 $\mathrm{mg} \mathrm{L}^{-1}$ a $702,1 \mathrm{mg} \mathrm{L}^{-1}$ ), sulfatos (de $40 \mathrm{mg} \mathrm{L}^{-1}$ a $1646 \mathrm{mg} \mathrm{L}^{-1}$ ) e cloretos (de $60 \mathrm{mg} \mathrm{L}^{-1}$ a 1053 $\left.\mathrm{mg} \mathrm{L}^{-1}\right)$. Apesar de tratar-se de um aquífero costeiro livre, a modelagem hidroquímica realizada com Phreeqc indicou baixo índice de mistura com água do mar, sendo da ordem de 0,35 \% a 4,67 \% (Ferreira et al., 2013).

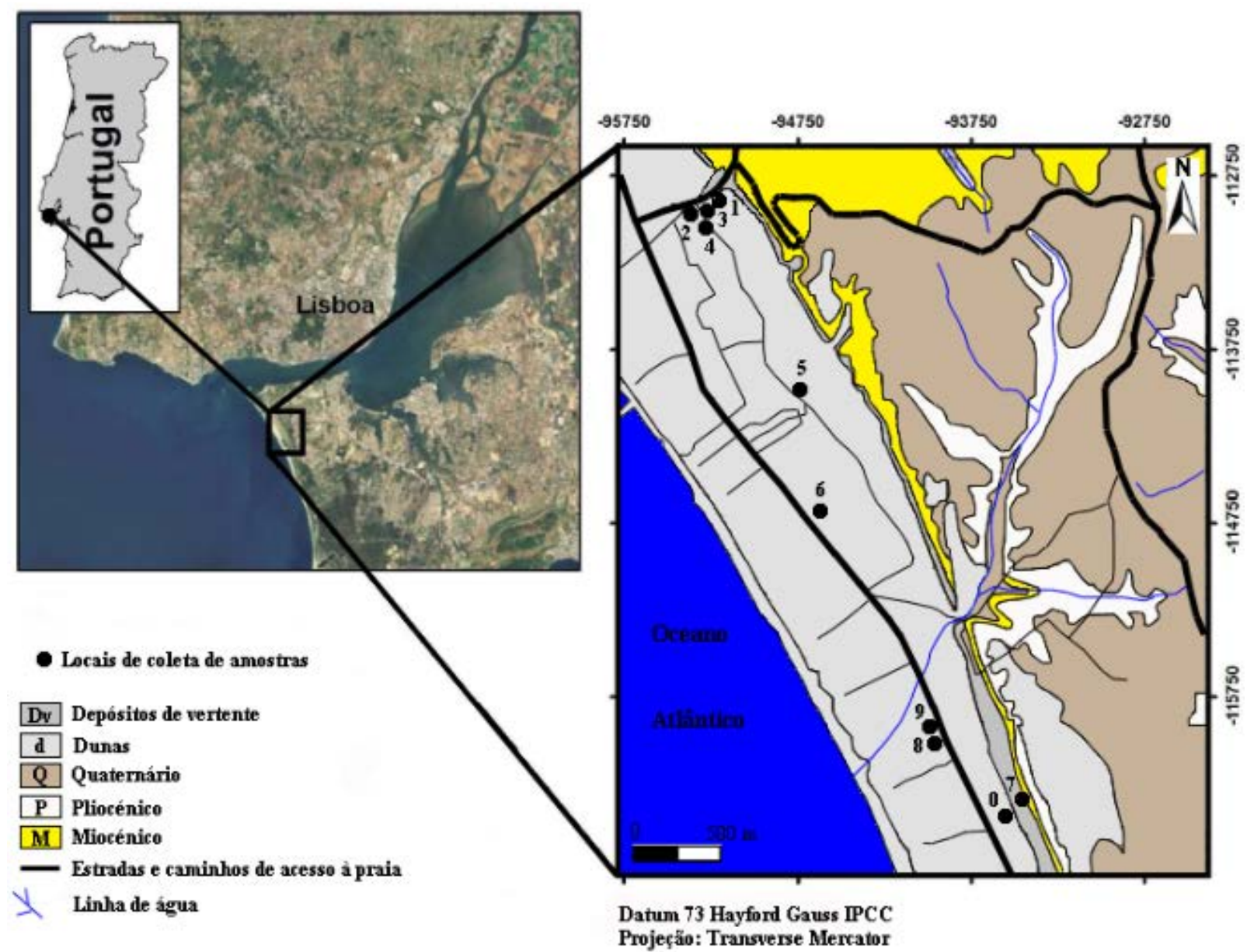

Figura 1 - Localização da área de estudo e dos locais de coleta de amostras (adaptado de Jorge et al. 2012).

\section{MATERIAIS E MÉTODOS}

Foram coletadas amostras em 10 locais situados na planície litorânea (Figura 1), na camada superficial e às profundidades de $10 \mathrm{e}$ $20 \mathrm{~cm}$, nas dunas com e sem manejo agrícola, segundo as normas ISO 10381-2 (ISO, 2002), ISO 10381-3 (ISO, 2001) e a norma ASTM D6232-08 (ASTM, 2008). As amostras foram acondicionadas em sacos plásticos, de cor preta, armazenadas e transportadas em caixas térmicas refrigeradas para o Laboratório de Geotecnia Ambiental (LGamb) do Laboratório Nacional de Engenharia Civil (LNEC), onde foram guardadas, a cerca de $4^{\circ} \mathrm{C}$, até serem analisadas.

Em todas as amostras foi determinado o teor em água ou umidade do solo (W), segundo a norma portuguesa NP 84 de 1965 (NP, 1965) e estimado o teor de matéria orgânica (MO), expresso em percentagem de peso seco, pelo método MAB - Peróxido (Bortolin \& Cassol, 2010). Na água do lixiviado das amostras foi determinado o $\mathrm{pH}$, o potencial de oxirredução (Eh) e a condutividade elétrica (CE), pela Especificação 203 do Laboratório Nacional de Engenharia Civil (LNEC, 1967). A fração fina, constituída pelas partículas siltoargilosas, foi determinada por peneiramento e admitida igual à percentagem de material que passa na peneira ASTM $n^{\circ} 200$, com abertura da malha igual a $0,074 \mathrm{~mm}$. A composição química foi determinada por fluorescência de raios X (FRX) com detector XL3t Thermo Scientific of Niton e tecnologia GOLD+, em modo Soil, em 3 provetas, com três disparos de 90 segundos de duração, sobre cada proveta, de acordo com o método 6200 de United States Environmental Protection Agency (EPA, 1998). 
Os resultados da composição química do solo foram submetidos à análise estatística de
Pearson e determinados os coeficientes de correlação (r).

\section{RESULTADOS E DISCUSSÃO}

As figuras 2 e 3 mostram os parâmetros físicos e químicos determinados nas amostras coletadas nas dunas com uso agrícola intenso desde o século XVIII (amostras 1 a 9) e na duna sem manejo agrícola (amostra 0).

No que se refere à granulometria das amostras, entre 90 \% e 100 \% da composição total, corresponde ao intervalo limitado pelos diâmetros de 0,074 e $2 \mathrm{~mm}$, sendo esta fração constituída por areia fina a média, quartzosa, bem calibrada, típica de areia de duna. O uso agrícola intenso das areias resultou num enriquecimento, ainda que pouco significativo, da fração silto-argilosa (amostras 1 a 9). A fração fina do solo, em superfície e à profundidade de 10 e $20 \mathrm{~cm}$, corresponde a menos de $1 \%$ da amostra (entre $0,0 \%$ e $0,9 \%$ ), com exceção para os locais de coleta das amostras 1 e 5 . O manejo agrícola e as condições do terreno poderão ser a causa para o efeito observado. Durante os trabalhos de campo constatou-se que a parcela agrícola onde foi coletada a amostra 5 não era arada entre os cultivos o que poderá explicar o acúmulo de partículas mais finas, em profundidade. O coeficiente de correlação (r) em relação à profundidade variou entre $0,10 \mathrm{e}$ -0,66, evidenciando heterogeneidade na distribuição da fração fina em profundidade.

O teor de água ou umidade do solo (W) aumentou com o manejo agrícola, de 0,0 \% para o valor máximo de $27,4 \%$, observado na amostra 1. A maior parte das amostras apresentou teor de matéria orgânica (MO) inferior a $2 \%$, com distribuição irregular. Em alguns casos foi observado o aumento de matéria orgânica com a profundidade e, em outros, o decréscimo. No caso do solo em pousio esse parâmetro diminuiu com a profundidade, apresentando correlação negativa $(r=-0,6)$.

A fração fina e a matéria orgânica tendem a aumentar com o manejo agrícola, determinando, em consequência, o aumento da retenção específica ou teor em água. As areias de duna são pobres em matéria orgânica e, como tal, metais pesados que sejam adicionados ao solo pelos agroquímicos não sofrem retenção, aumentando a sua mobilidade, biodisponibilidade e o risco ecotoxicológico (Van Put et al., 1994; Qishlaqi \& Moore, 2007; Tomáš et al., 2012).

$\mathrm{O}$ pH sofreu ligeiro decréscimo: de básico, na duna sem manejo agrícola $(\mathrm{pH}=8,9)$, para valores entre 7,4 e 8,7. Estes valores favorecem a biodisponibilidade média de metais pesados, uma vez que a MO se situa majoritariamente abaixo de $2 \%$.

O potencial de oxirredução (Eh) é típico de ambiente oxidante, com valor mínimo na duna sem agricultura (134 mV) e máximo na duna com manejo agrícola (268 mV). Alterações do Eh podem favorecer a formação de óxidos e hidróxidos de Fe e Mn, insolúveis, e aumentar a sua fixação, diminuindo a mobilidade e biodisponibilidade.

A condutividade elétrica tem comportamento irregular, aumentou com a umidade e a formação de solutos, de $37 \mu \mathrm{S} \mathrm{cm}$ ch $^{-1}$ para 2087 $\mu \mathrm{S} \mathrm{cm}^{-1}$. Numa das parcelas agrícolas não aradas (local de coleta 5) foi identificado processo de salinização superficial do solo, decorrente da irrigação com águas salobras (Martinez, 2010). O aumento de sais no solo pode ocorrer em função da adsorção de sódio presente na água de irrigação na forma dissolvida. De acordo com Martinez (2010), a água subterrânea extraída nesse terreno agrícola apresentou risco de salinização muito alto, com $4830 \mu \mathrm{S} \mathrm{cm}^{-1}$ de CE, e risco médio de sódio de acordo com a razão de adsorção de sódio SAR (US Salinity Laboratory, 1954). O autor indica que não é recomendado o uso dessa água para irrigação, podendo ser aplicada unicamente em solos com boa drenagem para evitar a adsorção de sódio. Solos mal drenados, com textura fina e elevada capacidade de troca iônica, elevam o risco de salinização.

De um modo geral, não se observou evidente correlação entre as características físicas e químicas e a profundidade. Porém no caso de valores inferiores de $\mathrm{pH}$ existe correlação negativa entre este e a condutividade elétrica $(r=-0,78)$, a matéria orgânica $(r=-0,70)$ e a umidade do solo $(r=$ $0,68)$. 


\begin{tabular}{|c|c|c|c|c|c|c|c|c|c|c|c|}
\hline Amostras & & $\begin{array}{c}\text { Fração } \\
<0,074 \\
(\mathrm{~mm})\end{array}$ & $\begin{array}{c}\text { Fração } \\
>2 \\
(\mathrm{~mm})\end{array}$ & $\begin{array}{c}\text { Fração } \\
0,074-2 \\
(\mathrm{~mm})\end{array}$ & $\begin{array}{l}W \\
(2)\end{array}$ & $\begin{array}{c}\text { MO } \\
\left(\mathrm{g} \mathrm{kg-}^{1}\right)\end{array}$ & $\begin{array}{l}\text { MO } \\
(\%)\end{array}$ & pH & $\begin{array}{c}\text { CE } \\
\mu S \mathbf{~ c m}^{-1}\end{array}$ & $\begin{array}{c}\text { Eh } \\
(\mathrm{mV})\end{array}$ & $\begin{array}{c}\text { Coordenadas* } \\
\mathbf{M} \\
\mathbf{P}\end{array}$ \\
\hline \multirow{4}{*}{ 0 } & $0 \mathrm{~cm}$ & (1) & (1) & (1) & $(1)$ & (1) & (1) & (1) & $(1)$ & $(1)$ & \\
\hline & $10 \mathrm{~cm}$ & $0,0 \%$ & $0,0 \%$ & $100,0 \%$ & $0,2 \%$ & 8,5 & 0,8 & 8,9 & 38,0 & 134,0 & 106,1 \\
\hline & $20 \mathrm{~cm}$ & $0,0 \%$ & $0,0 \%$ & $100,0 \%$ & $0,0 \%$ & 4,0 & 0,4 & 9,0 & 36,0 & 134,0 & 184,1 \\
\hline & Média & $0,0 \%$ & $0,0 \%$ & $100,0 \%$ & $0,1 \%$ & 6,3 & 0,6 & 9,0 & 37,0 & 134,0 & \\
\hline \multirow{4}{*}{1} & $0 \mathrm{~cm}$ & $(1)$ & $(1)$ & (1) & $(1)$ & $(1)$ & (1) & (1) & $(1)$ & $(1)$ & 104,6 \\
\hline & $10 \mathrm{~cm}$ & $7,3 \%$ & $0,3 \%$ & $92,4 \%$ & $27,4 \%$ & 28,7 & 2,8 & 7,8 & 605,0 & 243,0 & 187,2 \\
\hline & $20 \mathrm{~cm}$ & $2,8 \%$ & $0,6 \%$ & $96,6 \%$ & $23,1 \%$ & 29,3 & 2,9 & 7,6 & 979,0 & 205,0 & \\
\hline & Média & $5,1 \%$ & & & $25,2 \%$ & 29,0 & 2,9 & 7,7 & 792,0 & 224,0 & \\
\hline \multirow{4}{*}{2} & $0 \mathrm{~cm}$ & $(1)$ & (1) & (1) & (1) & $(1)$ & (1) & (1) & (1) & $(1)$ & 104,4 \\
\hline & $10 \mathrm{~cm}$ & $0,4 \%$ & $1,3 \%$ & $98,3 \%$ & $7,1 \%$ & 16,3 & 1,6 & 8,6 & 329,0 & 194,0 & 187,1 \\
\hline & $20 \mathrm{~cm}$ & $0,8 \%$ & $1,5 \%$ & $97,7 \%$ & $10,0 \%$ & 12,9 & 1,2 & 8,4 & 275,0 & 160,0 & \\
\hline & Média & $0,6 \%$ & & & $8,5 \%$ & 14,6 & 1,4 & 8,5 & 302,0 & 177,0 & \\
\hline \multirow{4}{*}{3} & $0 \mathrm{~cm}$ & $(1)$ & $(1)$ & $(1)$ & $(1)$ & $(1)$ & (1) & (1) & $(1)$ & $(1)$ & 104,5 \\
\hline & $10 \mathrm{~cm}$ & $0,9 \%$ & $0,0 \%$ & $99,1 \%$ & $4,7 \%$ & 10,2 & 1,0 & 8,3 & 204,0 & 157,0 & 187,6 \\
\hline & $20 \mathrm{~cm}$ & $0,2 \%$ & $0,5 \%$ & $99,3 \%$ & $4,5 \%$ & 18,1 & 1,8 & 8,2 & 348,0 & 189,0 & \\
\hline & Média & $0,6 \%$ & & & $4,6 \%$ & 14,2 & 1,4 & 8,3 & 276,0 & 173,0 & \\
\hline \multirow{4}{*}{4} & $0 \mathrm{~cm}$ & $(1)$ & $(1)$ & $(1)$ & $(1)$ & $(1)$ & (1) & (1) & $(1)$ & $(1)$ & 104,5 \\
\hline & $10 \mathrm{~cm}$ & $0,5 \%$ & $0,7 \%$ & $98,8 \%$ & $0,1 \%$ & 20,5 & 2,0 & 8,4 & 95,0 & 238,0 & 186,9 \\
\hline & $20 \mathrm{~cm}$ & $0,1 \%$ & $0,0 \%$ & $99,9 \%$ & $2,1 \%$ & 0,0 & 0,0 & 8,7 & 57,0 & 148,0 & \\
\hline & Média & $0,3 \%$ & & & $1,1 \%$ & 10,3 & 1,0 & 8,6 & 76,0 & 193,0 & \\
\hline \multirow{4}{*}{5} & $0 \mathrm{~cm}$ & $1,8 \%$ & $7,4 \%$ & $90,8 \%$ & $24,8 \%$ & 39,3 & 3,9 & 7,4 & 2400,0 & 200,0 & 105,1 \\
\hline & $10 \mathrm{~cm}$ & $3,0 \%$ & $1,4 \%$ & $95,6 \%$ & $21,8 \%$ & 19,7 & 1,9 & 7,4 & 2320,0 & 184,0 & 186,1 \\
\hline & $20 \mathrm{~cm}$ & $3,5 \%$ & $3,9 \%$ & $92,9 \%$ & $21,8 \%$ & 26,1 & 2,6 & 7,6 & 1861,0 & 205,0 & \\
\hline & Média & $2,8 \%$ & & & $22,8 \%$ & 28,4 & 2,8 & 7,5 & 2193,0 & 196,0 & \\
\hline \multirow{4}{*}{6} & $0 \mathrm{~cm}$ & $0,6 \%$ & $0,0 \%$ & $99,4 \%$ & $11,7 \%$ & 22,0 & 2,2 & 8,3 & 477,0 & 268,0 & 105,3 \\
\hline & $10 \mathrm{~cm}$ & $0,4 \%$ & $0,0 \%$ & $99,6 \%$ & $14,3 \%$ & 40,9 & 4,0 & 8,4 & 490,0 & 170,0 & 185,4 \\
\hline & $20 \mathrm{~cm}$ & $0,5 \%$ & $0,0 \%$ & $99,5 \%$ & $12,2 \%$ & 17,5 & 1,7 & 8,2 & 442,0 & 261,0 & \\
\hline & Média & $0,5 \%$ & $0,0 \%$ & & $12,7 \%$ & 26,8 & 2,6 & 8,3 & 470,0 & 233,0 & \\
\hline \multirow{4}{*}{7} & $0 \mathrm{~cm}$ & $0,3 \%$ & $8,3 \%$ & $91,4 \%$ & $6,9 \%$ & 10,2 & 1,0 & 8,3 & 298,0 & 157,0 & 105,7 \\
\hline & $10 \mathrm{~cm}$ & $0,4 \%$ & $7,3 \%$ & $92,3 \%$ & $8,4 \%$ & 13,6 & 1,3 & 8,4 & 101,0 & 193,0 & 184,1 \\
\hline & $20 \mathrm{~cm}$ & $0,5 \%$ & $8,6 \%$ & $90,9 \%$ & $8,9 \%$ & 16,3 & 1,6 & 8,1 & 134,0 & 203,0 & \\
\hline & Média & $0,4 \%$ & & & $8,1 \%$ & 13,4 & 1,3 & 8,3 & 177,0 & 184,0 & \\
\hline \multirow{4}{*}{8} & $0 \mathrm{~cm}$ & $0,8 \%$ & $0,7 \%$ & $98,5 \%$ & $0,8 \%$ & 25,6 & 2,5 & 7,6 & 373,0 & 202,0 & 105,7 \\
\hline & $10 \mathrm{~cm}$ & $0,3 \%$ & $1,4 \%$ & $98,3 \%$ & $2,1 \%$ & 18,5 & 1,8 & 8,0 & 446,0 & 200,0 & 184,0 \\
\hline & $20 \mathrm{~cm}$ & $0,4 \%$ & $1,1 \%$ & $98,5 \%$ & $2,6 \%$ & 20,6 & 2,0 & 8,0 & 437,0 & 195,0 & \\
\hline & Média & $0,5 \%$ & & & $1,8 \%$ & 21,6 & 2,1 & 7,9 & 419,0 & 199,0 & \\
\hline \multirow{4}{*}{9} & $0 \mathrm{~cm}$ & $0,7 \%$ & $0,4 \%$ & $98,9 \%$ & $1,3 \%$ & 23,6 & 2,3 & 8,1 & 461,0 & 159,0 & 106,2 \\
\hline & $10 \mathrm{~cm}$ & $0,3 \%$ & $0,1 \%$ & $99,6 \%$ & $1,0 \%$ & 6,7 & 0,6 & 8,6 & 132,0 & 195,0 & 184,1 \\
\hline & $20 \mathrm{~cm}$ & $0,5 \%$ & $0,0 \%$ & $99,5 \%$ & $1,1 \%$ & 3,2 & 0,3 & 8,7 & 131,0 & 150,0 & \\
\hline & Média & $0,5 \%$ & & & $1,1 \%$ & 11,2 & 1,1 & 8,5 & 241,0 & 168,0 & \\
\hline
\end{tabular}

Figura 2 - Granulometria e parâmetros físicos e químicos das amostras coletadas em dunas litorâneas situadas nas Terras da Costa, Caparica (Portugal); duna sem manejo agrícola (amostra 0); duna com prática agrícola intensa (amostras 1 a 9) (Jorge et al. 2012).

*Coordenadas na quadrícula quilométrica de Gauss, (1) - Sem amostragerm, (2) - Teor em água ou umidade, expresso em percentagem de peso seco.

A composição química das areias mostrou que estas sofreram acúmulo generalizado de íons $\mathrm{Fe}, \mathrm{Mn}, \mathrm{Zn}, \mathrm{Cu}, \mathrm{As}, \mathrm{Pb}, \mathrm{Cr}, \mathrm{Rb}, \mathrm{Zr}$, Th, Sr, U, Ni, Co, Hg e V, devido ao manejo agrícola intenso (Figura 4). Porém, não se observaram diferenças significativas em relação à profundidade, ou seja, tendência para acúmulo preferencial em qualquer dos horizontes amostrados (Figura 5). No entanto podem-se observar tendências crescentes de acúmulo dos íons $\mathrm{Mn}, \mathrm{Zn}, \mathrm{Cu}, \mathrm{Pb}, \mathrm{Cr}, \mathrm{Zr}$, Th, Sr, U, Ni e V, em função da profundidade.

$\mathrm{Na}$ duna sem atividade agrícola os íons $\mathrm{Fe}$, o $\mathrm{Mn}$, o $\mathrm{Zr}$, o $\mathrm{Sr}$ e o $\mathrm{Ni}$ sofreram ligeira estratificação e aumento com a profundidade. $\mathrm{O}$ processo de adsorção, favorecido pela presença de matéria orgânica, pode ser a causa desta observação, uma vez que a matéria orgânica também aumenta com a profundidade. Em relação aos demais parâmetros como fração fina, W, pH e Eh não foi verificada qualquer tendência significativa. 

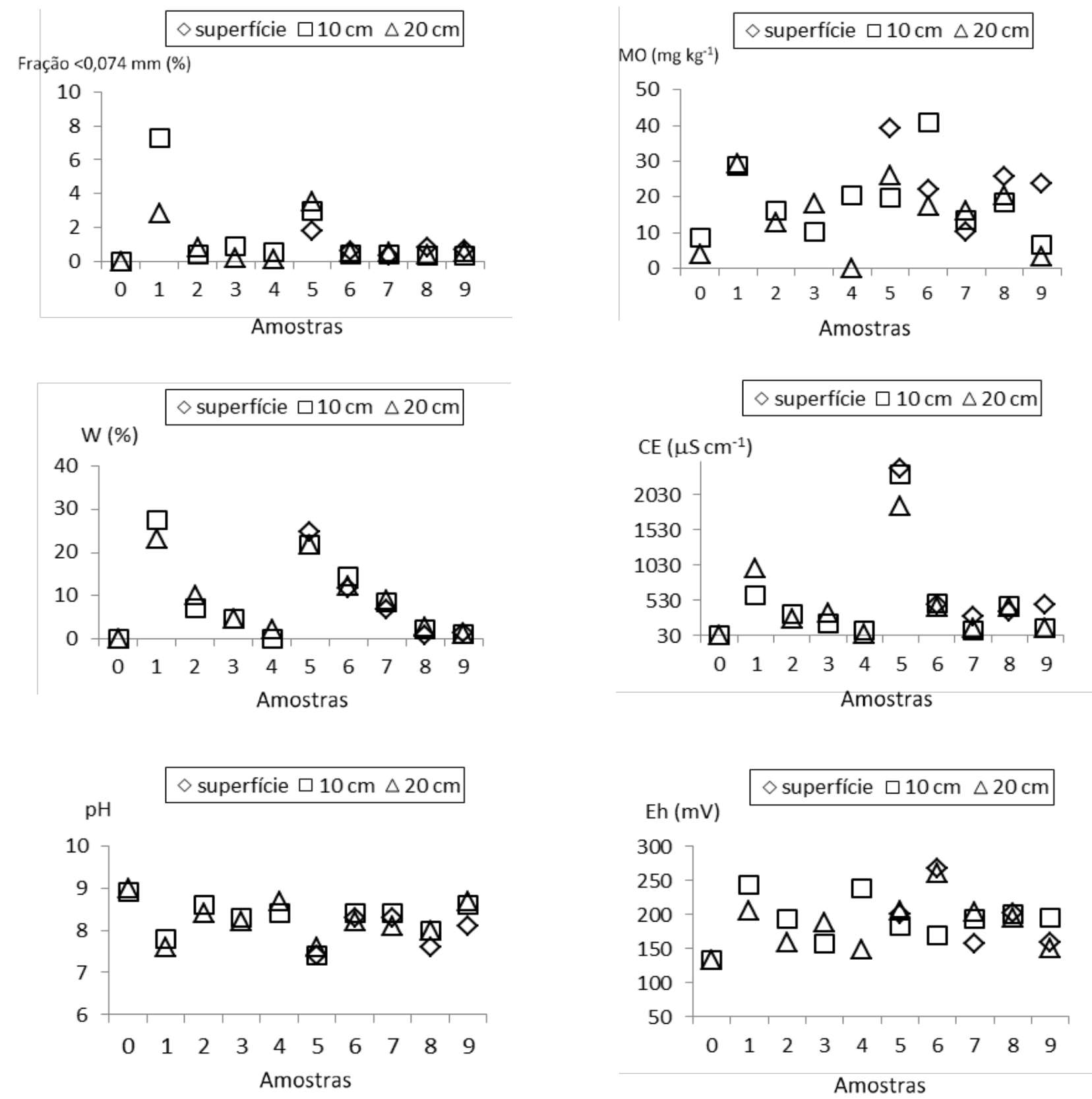

Figura 3 - Parâmetros físicos e químicos das areias de duna com manejo agrícola (amostras 1 a 9) e sem manejo agrícola (amostra 0).

O aumento da concentração de $\mathrm{Sr}, \mathrm{Ni}, \mathrm{Cr}$, $\mathrm{Mn}, \mathrm{Zn}, \mathrm{Cu}, \mathrm{Pb}$ e As pode estar relacionado com outras fontes de contaminação diferentes das atividades agrícolas. A presença destes íons metálicos é com frequência associada à poluição atmosférica em zonas industriais ou situadas próximo de rodovias com intensa circulação de veículos (Nicholson et al., 2003, 2010).

Na amostra 1 verificou-se estratificação com a profundidade, unicamente nas concentrações de $\mathrm{Cr}$ e U. Dos 10 para os $20 \mathrm{~cm}$ de profundidade, o $\mathrm{Cr}$ diminui e o U aumentou. A umidade (W) e o Eh diminuíram com a profun- didade e, de forma significativa, aumentou a percentagem da fração fina para 7,3 \%, o maior valor observado. A elevada concentração de $\mathrm{Cr}$ pode ser justificada pela adsorção deste às partículas silto-argilosas do solo.

$\mathrm{Na}$ amostra 3 observou-se maior concentração de $\mathrm{Cr}, \mathrm{Ni}, \mathrm{Co}, \mathrm{Hg}$ e $\mathrm{V}$, à maior profundidade, bem como o aumento de $\mathrm{MO}$ e de Eh. O ambiente mais oxidante, a $20 \mathrm{~cm}$ de profundidade, pode ter favorecido a imobilização destes metais sob a forma de óxidos insolúveis, visto que nesse ambiente os íons apresentam menor solubilidade (Núñes et al., 1999). 


\begin{tabular}{|c|c|c|c|c|c|c|c|c|c|c|c|c|c|c|c|c|c|}
\hline Amostras & & $\mathbf{F e}$ & Mn & $\mathrm{Cu}$ & Zn & $\mathbf{P b}$ & As & $\mathrm{Zr}$ & Th & $\mathbf{R b}$ & Sr & $\mathrm{Cr}$ & $\mathbf{V}$ & $\mathrm{Ni}$ & Hg & Co & $\mathbf{U}$ \\
\hline 0 & $0 \mathrm{~cm}$ & $(1)$ & (1) & (1) & $(1)$ & (1) & (1) & $(1)$ & (1) & (1) & $(1)$ & (1) & $(1)$ & (1) & (1) & (1) & (1) \\
\hline Duna & $10 \mathrm{~cm}$ & 6057,2 & 226,5 & 9,0 & 19,7 & 4,5 & 11,1 & 276,1 & 8,6 & 86,4 & 317,7 & 24,5 & $<39,7$ & 38,8 & $<5,6$ & - & - \\
\hline Não & $20 \mathrm{~cm}$ & 4181,2 & 158,3 & -- & 14,4 & -- & 9,8 & 59,0 & 4,3 & 87,5 & 304,5 & 21,8 & -- & 36,5 & $<4,0$ & -- & -- \\
\hline cultivada & Média & 5119,2 & 192.4 & 9,0 & 17,0 & 4,5 & 10,5 & 167,5 & 6,4 & 86,9 & 311,1 & 23,1 & & 37,6 & & & \\
\hline 1 & $0 \mathrm{~cm}$ & (1) & $(1)$ & $(1)$ & $(1)$ & (1) & (1) & $(1)$ & $(1)$ & $(1)$ & $(1)$ & $(1)$ & (1) & $(1)$ & $(1)$ & (1) & (1) \\
\hline Duna & $10 \mathrm{~cm}$ & 12073,3 & 137,6 & 15,5 & 58,2 & 9,4 & 14,3 & 657,3 & 30,4 & 135,3 & 98,1 & 25,5 & -- & $<23,4$ & $<5,1$ & -- & 8,5 \\
\hline \multirow[t]{2}{*}{ Cultivada } & $20 \mathrm{~cm}$ & 11963,6 & 128,4 & 13,3 & 60,9 & 7,3 & 16,7 & 574,5 & 28,8 & 134,9 & 98,3 & 18,4 & -- & -- & -- & -- & 10,9 \\
\hline & Média & 12018,4 & 133,0 & 14,4 & 59,5 & 8,4 & 15,5 & 615,9 & 29,6 & 135,1 & 98,2 & 21,9 & & & & & 9,7 \\
\hline \multirow{4}{*}{$\begin{array}{c}2 \\
\text { Duna } \\
\text { Cultivada }\end{array}$} & $0 \mathrm{~cm}$ & (1) & (1) & $(1)$ & $(1)$ & (1) & (1) & $(1)$ & $(1)$ & $(1)$ & $(1)$ & $(1)$ & (1) & $(1)$ & (1) & (1) & (1) \\
\hline & $10 \mathrm{~cm}$ & 8170,5 & 148,2 & 18,1 & 66,0 & 26,2 & 11,8 & 860,9 & 40,0 & 123,9 & 110,7 & -- & -- & $<31,9$ & - & -- & 9,6 \\
\hline & $20 \mathrm{~cm}$ & 8938,5 & 148,2 & 20,7 & 75,7 & 29,8 & 12,2 & 850,8 & 43,0 & 126,8 & 113,9 & -- & -- & $<32,8$ & $<4,9$ & -- & 10,0 \\
\hline & Média & 8554,5 & 148,2 & 19,4 & 70,8 & 28,0 & 12,0 & 855,8 & 41,5 & 125,3 & 112,3 & & & & & & 9,8 \\
\hline \multirow{4}{*}{$\begin{array}{c}3 \\
\text { Duna } \\
\text { Cultivada }\end{array}$} & $0 \mathrm{~cm}$ & (1) & $(1)$ & $(1)$ & $(1)$ & $(1)$ & $(1)$ & $(1)$ & $(1)$ & $(1)$ & $(1)$ & $(1)$ & (1) & $(1)$ & (1) & $(1)$ & (1) \\
\hline & $10 \mathrm{~cm}$ & 11541,0 & 177,4 & 20,1 & 66,2 & 10,6 & 13,6 & 627,4 & 23,1 & 119,2 & 132,4 & 16,1 & -- & 28,9 & 4,6 & 61,5 & 6,5 \\
\hline & $20 \mathrm{~cm}$ & 12214,2 & 137,0 & 17,0 & 69,0 & 6,9 & 12,4 & 454,0 & 21,1 & 120,3 & 136,6 & 51,0 & 47,4 & 40,3 & -- & -- & $<5,0$ \\
\hline & Média & 11877,6 & 157,2 & 18,5 & 67,6 & 8,7 & 13,0 & 540,7 & 22,1 & 119,7 & 134,5 & 33,5 & 47,4 & 34,6 & & & \\
\hline \multirow{4}{*}{\begin{tabular}{|c|}
4 \\
Duna \\
Cultivada)
\end{tabular}} & $0 \mathrm{~cm}$ & (1) & $(1)$ & $(1)$ & $(1)$ & $(1)$ & (1) & $(1)$ & $(1)$ & $(1)$ & $(1)$ & (1) & $(1)$ & $(1)$ & (1) & $(1)$ & (1) \\
\hline & $10 \mathrm{~cm}$ & 11717,1 & 353,3 & 41,1 & 92,1 & 15,9 & 14,8 & 994,6 & 66,4 & 120,3 & 188,5 & 49,4 & $<37,7$ & -- & -- & 57,8 & 10,1 \\
\hline & $20 \mathrm{~cm}$ & 13744,2 & 454,1 & 30,8 & 69,3 & 12,3 & 14,4 & 1965,1 & $90 ., 9$ & 123,6 & 150,9 & 48,8 & $<59,8$ & $<34,3$ & -- & -- & 21,9 \\
\hline & Média & 12730,6 & 403,7 & 35,9 & 80,7 & 14,1 & 14,6 & 1479,8 & 78,6 & 121,9 & 169,7 & 49,1 & & & & 57,8 & 16,0 \\
\hline \multirow{4}{*}{$\begin{array}{c}5 \\
\text { Duna } \\
\text { Cultivada }\end{array}$} & $0 \mathrm{~cm}$ & 8842,6 & 133,1 & 26,5 & 112,1 & 38,1 & 10,7 & 673,9 & 30,1 & 125,4 & 186,9 & & -- & -- & $<4,4$ & -- & 8,4 \\
\hline & $10 \mathrm{~cm}$ & 9119,7 & 136,8 & 23,6 & 110,7 & 38,7 & 10,3 & 728,2 & 34,3 & 131,3 & 128,7 & 27,7 & -- & $<29,9$ & -- & -- & 8,9 \\
\hline & $20 \mathrm{~cm}$ & 9176,2 & 123,6 & 24,3 & 115,0 & 40,1 & 10,8 & 739,3 & 35,1 & 131,6 & 136,2 & 17,8 & -- & -- & $<4,2$ & -- & 10,9 \\
\hline & Média & 9046,1 & 131,1 & 24,8 & 112,6 & 38,9 & 10,6 & 713,8 & 33,1 & 129,4 & 150,6 & 22,7 & & & & & 9,4 \\
\hline \multirow{4}{*}{$\begin{array}{c}6 \\
\text { Duna } \\
\text { Cultivada }\end{array}$} & $0 \mathrm{~cm}$ & 24623,3 & 250,0 & 22,8 & 92,3 & 10,1 & 35,3 & 417,2 & 21,9 & 158,7 & 155,8 & 35,0 & 67,7 & -- & $<6,7$ & 82,9 & -- \\
\hline & $10 \mathrm{~cm}$ & 25862,8 & 240,3 & 18,3 & 95,0 & 9,6 & 35,3 & 405,8 & 19,3 & 161,4 & 146,9 & 36,6 & 50 & $<33,4$ & -- & 92,4 & 7,4 \\
\hline & $20 \mathrm{~cm}$ & 26707,3 & 247,5 & 23,1 & 101,6 & 12,1 & 38,6 & 382,8 & 16,9 & 162,2 & 149,8 & 47,7 & 69,9 & 30,2 & 5,6 & 91,9 & -- \\
\hline & Média & 25731,1 & 245,9 & 21,4 & 96,3 & 10,6 & 36,4 & 401,9 & 19,3 & 160,7 & 150,8 & 39,7 & 62,5 & 30,2 & 5,6 & 89,0 & 7,4 \\
\hline \multirow{4}{*}{$\begin{array}{c}7 \\
\text { Duna } \\
\text { Cultivada }\end{array}$} & $0 \mathrm{~cm}$ & 10352,4 & 164,6 & 18,6 & 54,8 & 17,7 & 11,4 & 767,2 & 34,1 & 190,6 & 90,0 & 15,9 & $<33,8$ & -- & -- & -- & 7,9 \\
\hline & $10 \mathrm{~cm}$ & 9827,1 & 162,0 & 13,5 & 57,9 & 18,3 & 11,0 & 831,8 & 32,1 & 190,7 & 87,7 & 23,9 & $<43,7$ & -- & $<4,1$ & -- & $<8,8$ \\
\hline & $20 \mathrm{~cm}$ & 9596,6 & 175,7 & 20,8 & 60,6 & 15,9 & 11,7 & 950,2 & 45,2 & 185,9 & 86,6 & 19,0 & $<39,6$ & -- & -- & -- & 12,7 \\
\hline & Média & 9925,3 & 167,4 & 17,6 & 57,7 & 17,3 & 11,4 & 849,7 & 37,1 & 189,0 & 88,1 & 19,6 & & & & & 10,3 \\
\hline \multirow{4}{*}{$\begin{array}{c} \\
\text { Duna } \\
\text { Cultivada }\end{array}$} & $0 \mathrm{~cm}$ & 15752,4 & 233,1 & 33,7 & 118,2 & 15,2 & 19,8 & 338,4 & 14,9 & 149,5 & 174,1 & 32,2 & 45,9 & -- & -- & -- & -- \\
\hline & $10 \mathrm{~cm}$ & 15707,1 & 243,8 & 36,4 & 115,5 & 13,8 & 20,5 & 323,3 & 17,2 & 148,7 & 183,5 & 35,9 & 47,0 & -- & $<4,0$ & -- & -- \\
\hline & $20 \mathrm{~cm}$ & 15618,2 & 233,1 & 38,5 & 117,1 & 14,1 & 20,6 & 313,6 & 15,3 & 149,4 & 183,6 & 35,1 & 52,9 & -- & -- & -- & -- \\
\hline & Média & 15692,5 & 236,6 & 36,2 & 116,9 & 14,4 & 20,3 & 487,6 & 15,8 & 149,2 & 180,4 & 34,4 & 48,6 & & & & \\
\hline \multirow{4}{*}{$\begin{array}{c}9 \\
\text { Duna } \\
\text { Cultivada }\end{array}$} & $0 \mathrm{~cm}$ & 12117,5 & 285,2 & 53,5 & 176,3 & 22,1 & 17,3 & 432,4 & 16,7 & 122,5 & 201,6 & 25,4 & 41,4 & -- & $<4,6$ & -- & -- \\
\hline & $10 \mathrm{~cm}$ & 11865,6 & 255,4 & 71,6 & 186,8 & 28,2 & --- & 427,0 & 29,4 & 134,1 & 241,1 & 28,4 & 55,6 & $<24,8$ & -- & -- & 8,4 \\
\hline & $20 \mathrm{~cm}$ & 10671,2 & 205,0 & 37,5 & 85,7 & 18,1 & 17,1 & 579,2 & 25,7 & 142,3 & 169,5 & 20,6 & 42,7 & -- & -- & -- & 7,9 \\
\hline & Média & 11551,4 & 248,5 & 54,2 & 149,6 & 22,8 & 17,2 & 479,5 & 23,9 & 132,9 & 204,0 & 24,8 & 46,5 & & & & 8,1 \\
\hline
\end{tabular}

Figura 4 - Metais analisados por FRX, em amostras de dunas litorâneas das Terras da Costa, Caparica (Portugal), valores em $\mathrm{mg} \mathrm{kg}^{-1}$. (1) - Sem amostragem.

Na amostra 4 o Fe, Mn, Zr, Th, U e Co apresentam comportamento semelhante, de aumento com a profundidade. No caso do Zn, $\mathrm{Cu}, \mathrm{Pb}$ e $\mathrm{Sr}$, as maiores concentrações ocorrem a $10 \mathrm{~cm}$ de profundidade. A matéria orgânica e o Eh diminuem com a profundidade, parecendo exercer maior efeito na adsorção do $\mathrm{Zn}, \mathrm{Cu}, \mathrm{Pb}$ e $\mathrm{Sr}$.

$\mathrm{Na}$ amostra 5 o $\mathrm{Cr}$ e o $\mathrm{Sr}$ ficam retidos à superfície, em resultado da fraca lixiviação ou maior retenção superficial. $\mathrm{Na}$ amostra 6 o $\mathrm{Cr}$ aumenta com a profundidade e foi detectada a presença de $\mathrm{Ni}$, Co e Hg. Na amostra 9 o Eh diminuiu com a profundidade e o ambiente torna-se mais redutor, como consequência aumenta a mobilidade de alguns metais podendo explicar a diminuição com a profundidade das concentrações de Fe, Mn, Zn, Cu, Pb, Cr, Sr e V.

$\mathrm{O}$ valor do Eh, $\mathrm{pH}$ e a presença de matéria orgânica são os parâmetros que mais interferem na fixação e mobilização destes metais nos horizontes amostrados, ou seja, até os $20 \mathrm{~cm}$ de profundidade, verificando-se uma tendência moderada para a existência de correlação positiva ou negativa entre a concentração de Fe, As, $\mathrm{Cu}, \mathrm{Zn}$ e o Rb, a matéria orgânica, o pH e o Eh (Figura 6).

Considerando a alteração das características físicas e químicas das areias de duna em função do fator multiplicativo do acúmulo de metais até os $20 \mathrm{~cm}$ de profundidade (Figura 7), verifica-se que o $\mathrm{Rb}$ e o Mn duplicaram (2,1x) a sua concentração, o Cr quase duplica $(1,7 x)$ e o As mais que triplica $(3,5 \mathrm{x})$. $\mathrm{O}$ aumento desses elementos no solo eleva o risco de ingestão por parte do consumidor de produtos hortícolas e torna necessária a aplicação de medidas para a proteção do consumidor ou para a utilização residencial desse espaço. $\mathrm{O} \mathrm{Fe}$ quintuplicou (5,0x) e o Cu sextuplicou (6,0x). O Pb, o Zn e o Zr octuplicaram, sendo o fator multiplicativo de 8,6 e 8,8 respectivamente. 


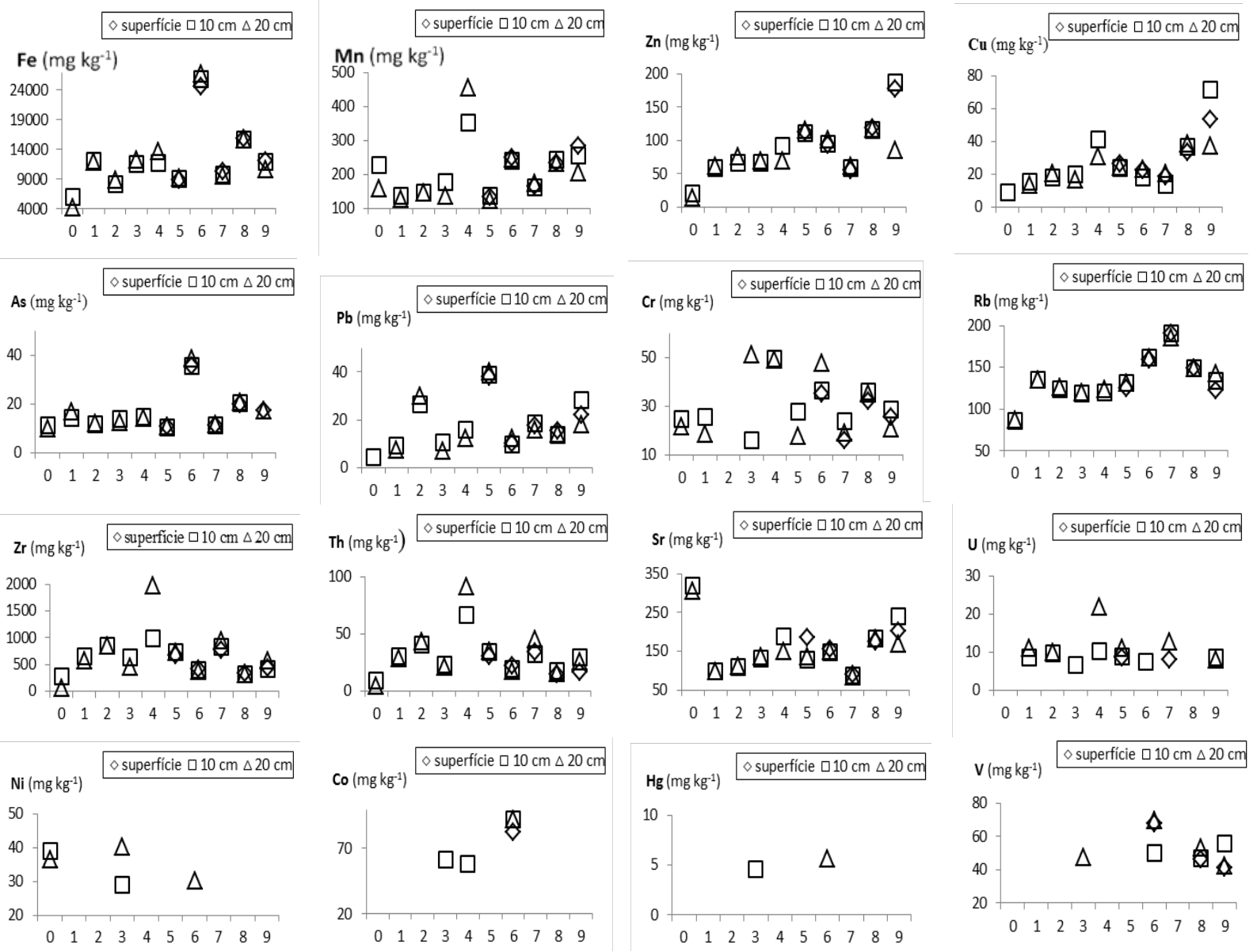

Figura 5 - Metais (Fe, Mn, Zn, Cu, As, Pb, Cr, Rb, Zr, Th, Sr, U, Ni, Co, Hg e V) analisados por FRX em amostras coletadas na duna sem manejo agrícola (amostra 0) e com manejo agrícola (amostras 0 a 9).
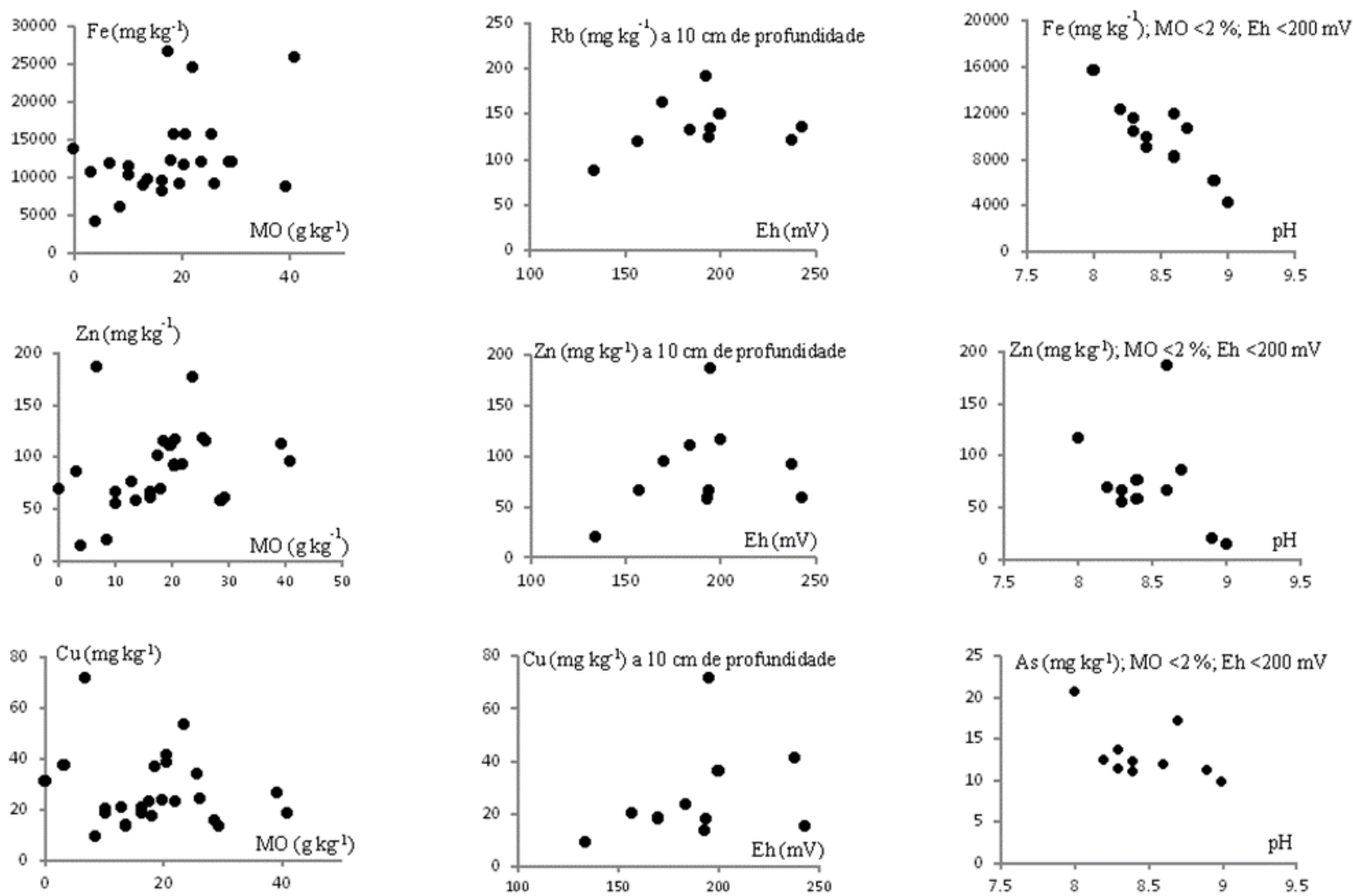

Figura 6. Correlação entre a concentração de $\mathrm{Fe}, \mathrm{Rb}, \mathrm{Zn}$, Cu e As, a matéria orgânica (MO), o potencial de oxirredução (Eh) e o pH nas amostras coletadas nas dunas litorâneas das Terras da Costa, Caparica (Portugal). 


\begin{tabular}{|c|c|c|c|c|c|c|c|c|c|c|c|c|}
\hline Amostras & $\mathbf{F e}$ & Mn & $\mathrm{Cu}$ & Zn & $\mathbf{P b}$ & As & $\mathrm{Zr}$ & Th & $\mathbf{R b}$ & $\mathrm{Sr}$ & $\mathrm{Cr}$ & $\mathrm{Ni}$ \\
\hline $\mathbf{0}(*)$ & 5119,2 & 192,4 & 9,0 & 17,0 & 4,5 & 10,5 & 167,5 & 6,4 & 86,9 & 311,1 & 23,1 & 37,6 \\
\hline $1(* *)$ & 2,3 & 0,7 & 1,6 & 3,5 & 1,8 & 1,4 & 3,6 & 4,6 & 1,5 & 0,3 & 0,9 & ND \\
\hline $2(* *)$ & 1,6 & 0,7 & 2,1 & 4,1 & 6,2 & 1,1 & 5,1 & 6,4 & 1,4 & 0,3 & ND & ND \\
\hline $3(* *)$ & 2,3 & 0,8 & 2,0 & 3,9 & 1,9 & 1,2 & 3,2 & 3,4 & 1,3 & 0,4 & 1,4 & 0,9 \\
\hline $4(* *)$ & 2,4 & 2,0 & 3,9 & 4,7 & 3,1 & 1,3 & 8,8 & 12,2 & 1,4 & 0,5 & 2,1 & ND \\
\hline $5(* *)$ & 1,7 & 0,6 & 2,7 & 6,6 & 8,6 & 1,0 & 4,2 & 5,1 & 1,4 & 0,4 & 0,9 & ND \\
\hline $6(* *)$ & 5,0 & 1,2 & 2,3 & 5,6 & 2,3 & 3,4 & 2,3 & 3,0 & 1,8 & 0,4 & 1,7 & 0,8 \\
\hline $7(* *)$ & 1,9 & 0,8 & 1,9 & 3,3 & 3,8 & 1,0 & 5,0 & 5,7 & 2,1 & 0,2 & 0,8 & ND \\
\hline $8(* *)$ & 3,0 & 1,2 & 4,0 & 6,8 & 3,2 & 1,9 & 2,9 & 2,4 & 1,7 & 0,5 & 1,4 & ND \\
\hline $9(* *)$ & 2,2 & 1,2 & 6,0 & 8,8 & 5,0 & 1,6 & 2,8 & 3,7 & 1,5 & 0,6 & 1,0 & ND \\
\hline
\end{tabular}

Figura 7 - Fator multiplicativo da concentração de metais nas dunas com uso agrícola relativamente à concentração destes na duna sem uso agrícola. Valores em $\mathrm{mg} \mathrm{kg}^{-1}$. (**) Fator multiplicativo da concentração total do elemento químico nas amostras de duna litorânea nas Terras da Costa, Caparica (Portugal) em relação ao valor de referência (*) determinado na amostra de duna sem uso agrícola. (ND) - não detetado por FRX.

No caso do Th, duo decuplicou $(12,2 x)$ a sua concentração na areia de duna com manejo agrícola, sofrendo o maior aumento entre os elementos analisados. Na duna com manejo agrícola, em algumas situações, as concentrações de $\mathrm{Sr}$ e $\mathrm{Cr}$ são inferiores às observadas na duna sem prática agrícola, indicando a possibilidade de coexistirem no local outras fontes de contaminação. Estes íons são frequentemente associados às emissões de automóveis. No caso da área de estudo, o local é atravessado por rodovias que permitem o acesso às praias e apresentam intenso tráfego de veículos durante a época balnear.
Em todas as amostras observa-se uma forte correlação positiva entre as concentrações de $\mathrm{Zr}$ e Th $(r>0,96)$; entre Cu e $\mathrm{Zn}(r>0,96)$; e entre $\mathrm{Cu}, \mathrm{Pb}, \mathrm{Sr}$ e $\mathrm{Zn}(\mathrm{r}>0,90)$, sendo superior a 0,97 no caso do $\mathrm{Cu}, \mathrm{Pb}$ e $\mathrm{Sr}$.

$O$ efeito da irrigação determina uma correlação quase perfeita $(r>0,99)$ e no caso do As e do $\mathrm{Fe}$, para qualquer profundidade. $\mathrm{O}$ acúmulo destes metais é maior nas dunas com manejo agrícola, em média 8,4 vezes para $\mathrm{Cu}$, 6,4 para $\mathrm{Zn}$ e 10,2 para o $\mathrm{Pb}$. As areias de duna sofreram indiscutível acúmulo de $\mathrm{Zr}$, Th $\mathrm{Cu}$ e $\mathrm{Zn}$ e, em menor quantidade, de $\mathrm{Mn}$, como resultado do uso agrícola intenso.

\section{CONCLUSÕES}

O estudo das dunas litorâneas das Terras da Costa, Caparica (Portugal), utilizadas ao longo de dois séculos pela população residente para uso agrícola, constatou que as dunas sofreram alterações na composição física e química, incluindo o acúmulo de íons metálicos.

O manejo agrícola resultou no aumento da fração fina (partículas inferiores a 0,074 mm), do conteúdo de matéria orgânica, do teor de umidade, da condutividade elétrica e do potencial de oxirredução. $\mathrm{O}$ pH sofreu ligeiro decréscimo, de básico para próximo de neutro, aumentando o risco de mobilidade dos íons metálicos.

Não se observou variabilidade significativa dos parâmetros físico-químicos em função da profundidade. Porém, para os valores mais baixos de $\mathrm{pH}$, foi observada forte correlação entre a presença de matéria orgânica e o aumento da umidade.

A maior parte das amostras apresentou baixa percentagem de matéria orgânica $(<2$ \%) que, associada à diminuição do $\mathrm{pH}$, propicia condições favoráveis para a mobilização de íons metálicos, aumentando o risco ecotoxicológico com o aumento da biodisponibilidade. Nessas condições, não é recomendável a prática agrícola em dunas.

Nas dunas com manejo agrícola foi constatado o acúmulo generalizado de metais no solo. Destaca-se o aumento de $\mathrm{Fe}, \mathrm{Mn}, \mathrm{Cu}$, $\mathrm{Zn}, \mathrm{Pb}, \mathrm{As}, \mathrm{Zr}$, Th, Rb, Cr, V, Ni, Hg, Co e U. $\mathrm{O} \mathrm{Rb}$ e o Mn duplicaram a concentração, o As triplicou, o Fe quintuplicou, $\mathrm{Cu}$ sextuplicou, o $\mathrm{Pb}, \mathrm{Zn}$ e o $\mathrm{Zr}$ octuplicaram e o Th duo decuplicou. Foram detectadas concentração de As superiores a $10 \mathrm{mg} \mathrm{kg}^{-1}$, representando risco toxicológico para o receptor/consumidor, em caso de ingestão.

Maiores concentrações de Sr e Cr na areia de duna sem prática agrícola indicam outras fontes prováveis de contaminação. Estas podem estar 
relacionadas com a precipitação de partículas emitidas por automóveis, uma vez que a região é muito procurada na época balnear e o tráfego é intenso nos meses de verão.

\section{AGRADECIMENTOS}

Este trabalho foi realizado no âmbito de uma colaboração entre o Laboratório Nacional de Engenharia Civil (LNEC), Portugal, a Faculdade de Ciências e Tecnologia da Universidade Nova de Lisboa, Portugal (FCT, UNL), o Centro de Investigação em Geociências, Geoengenharia e Geotecnologias (Geobiotec) e o Instituto de Pesquisas Tecnológicas do Estado de São Paulo, Brasil (IPT).

\section{REFERÊNCIAS}

ASTM - American Society for Testing and Materials. Standard Guide for Selection of Sampling Equipment for Waste and Contaminated Media Data Collection Activities, D6232-08. ASTM International, West Conshohocken, PA, 2008.

ALLOWAY, B.J. Soil processes and the behaviour of metals. In: Alloway B.J. (Editores). Heavy metals in soils. Glasgow, Blackie and Son, p.1-53, 1990.

BAŠIĆ, F.; KISIĆ, I.; MESIĆ, M.; HEAV, Y. Metals in Agricultural Soils and Food Chain. Department of General Agronomy, Faculty of Agriculture, University of Zagreb, Croatia, 2001.

BAHRAMPOOR, T. Concentration of some heavy metals $(\mathrm{Cu}$, $\mathrm{Zn}, \mathrm{Fe}, \mathrm{Mn}, \mathrm{Pb}, \mathrm{Cd}$ and $\mathrm{Ni}$ ) in arable lands of Mogha. International Journal of Food Agriculture and Veterinary Sciences, v. 2, n. 3, p. 146-152, 2012.

BLANES, R.L. Caracterização Sócio-cultural dos Agricultores das Terras da Costa. Costa de Caparica, 2003, 90p. Relatório de Estágio - Instituto de Conservação da Natureza e Conselho de Reitores das Universidades Portuguesas.

BLUME, H.P. \& BRÜMMER, G. Prediction of heavy metals behavior in soil by means of simple field tests. Ecotoxicology and Environmental Safety, v. 22 (Issue 2), p.164-174, 1991.

BORTOLIN, M.A. \& CASSOL, L.C. Determinação da matéria orgânica do solo usando peróxido de hidrogénio: Uma metodologia ecologicamente correta. In: FERTBIO, Guarapari, 2010. Anais...Guarapari: CD-ROM.

CARIA, G.G.; OLIVEIRA, M.M.; SILVA, C.R. Síntese do estudo da recarga de águas subterrâneas do concelho de Almada. In: SEMINÁRIO DE ÁGUAS SUBTERRÂNEAS DA ASSOCIAÇÃO PORTUGUESA DE RECURSOS HÍDRICOS, 9, Lisboa. Livro de Resumos...Lisboa, p. 3-6, 2013.

DECRETO LEI 168/84 - Área protegida por Portugal sob a designação de Paisagem Protegida da Arriba Fóssil da Costa da Caparica. Decreto Lei 168/84, de 22 de Maio. Diário da Republica - 1 . $^{\text {a }}$ Serie, n 118, de 22.05. p. 1646, 1984.

Eça, P. Freguesia da Caparica. Algumas notas sobre a sua agricultura e vida rural. Junta de Freguesia da Caparica, 1939.

LNEC - Laboratório Nacional de Engenharia Civil. Especificação 203: Solos, Determinação de pH. Lisboa: Laboratório Nacional de Engenharia Civil, Ministério das Obras Públicas, 1967.

EPA - Environmental Protection Agency. Method 6200 Field Portable X-Ray Fluorescence Spectrometry for the Determination of Elemental Concentration in Soil and Sediment. U.S., Environmental Protection Agency, Washington, DC, 1998.

FERREIRA, F.; CARVALHO, M.R.; SIMÕES, M.; SILVA, C.R.; GALEGO FERNANDES, P. Características hidroquímicas e hidrodinâmicas do aquífero superficial da planície arenosa da Costa de Caparica. In: SEMINÁRIO DE ÁGUAS SUBTERRÂNEAS DA ASSOCIAÇÃO
PORTUGUESA DE RECURSOS HÍDRICOS, 9, 2013. Lisboa. Livro de Resumos...Lisboa: p. 22-25.

GUPTA, N.; KHAN, D.K.; SANTRA, S.C. Heavy metal accumulation in vegetables grown in a long-term wastewaterirrigated agricultural land of tropical India. Environmental Monitoring and Assessment, v. 184 (Issue 11), p. 66736682, 2011

GIMENO-GARCÍA, E.; ADREU, V.; BOLUDA, R. Heavy metals incidence in the application of inorganic fertilizers and pesticides to rice farming soils. Environmental Pollution v. 92 (Issue 1), p. 19-25, 1996.

IINERT - In-Place Inactivation and Natural Ecological Restoration Technologies. Soils-Metals Action Teams. U.S. Environmental Protection Agency (EPA), 2006.

ISO (a) - International Organization for Standardization. Soil Quality: Sampling, Part 3. Guidance on Safety. International Standard 10381-3. Geneva. International Organization for Standardization, 2001.

ISO (b) - International Organization for Standardization. Soil Quality: Sampling, Part 2. Guidance on Sampling Techniques. International Standard 10381-2. Geneva. International Organization for Standardization, 2002.

JÄRUP, L. Hazards of heavy metal contamination. British Medical Bulletin v. 68 (Issue 1), p.167-182, 2003.

JORGE, C.; MANCUSO, M.; SIMÕES, M.; MARTINEZ, J. Metais presentes em solos sujeitos a práticas agrícolas continuadas. Terras da Costa da Caparica - Portugal. In: CONGRESSO NACIONAL DE GEOTECNIA, XIII 16p., 2012.

KABATA-PENDIAS, A. Trace elements in soils and plants. CRC Press, Taylors \& Francis Group, Boca Raton, U.S.A., $4^{\text {th }}$ Edition, 534p., 2011.

NP - Normas Portuguesas. Determinação do Teor em Água. Norma 84. Lisboa, Instituto Português da Qualidade, 1965.

MARTINEZ, J.L. Análise da viabilidade de aplicação de tecnologias de remediação ambiental in situ para redução da concentração de nitratos em águas subterrâneas, Costa da Caparica, Portugal. São Paulo, 2010, 233p. Tese (Mestrado em Tecnologia Ambiental), Instituto de Pesquisas Tecnológicas de São Paulo.

MISA - Minnesota Institute for Sustainable Agriculture. Urban gardens and soils contaminants, 2010. Disp. em: http://www.misa.umn.edu. Acessado em janeiro 2012.

NICHOLSON, F.; ROLLETT, A.; CHAMBERS, B. Quantifying heavy metals inputs from organic and inorganic material additions to agricultural soils in England and Wales. In: WORLD CONGRESS OF SOIL SCIENCE, SOIL SOLUTIONS FOR A CHANGING WORLD, 19, 2010, Brisbane. DVD. International Union of Soil Sciences, p. 186188

NICHOLSON, F.A.; SMITH, S.R.; ALLOWAY, B.J.; CARLTON-SMITH, C.; CHAMBERS, B.J. An inventory of heavy metals inputs to agricultural soils in England and Wales. The Science of the Total Environmental, v. 311, p. 205-219, 2003. 
NÚŇES, J.E.V.; AMARAL SOBRINHO, N.M.B.; PALMIERI, F.; MESQUITA, A.A. Conseqüências de diferentes sistemas de preparo do solo sobre a contaminação do solo, sedimentos e água por metais pesados. Revista Brasileira de Ciência do Solo, v. 23, n. 4, p. 981-990, 1999.

QISHLAQI, A. \& MOORE, F. Statistical Analysis of Accumulation and Sources of Heavy Metals Occurrence in Agricultural Soils of Khoshk River Banks, Shiraz, Iran. American-Eurasian Journal of Agricultural \& Environmental Sciences, v. 2, n. 5, p. 565-573, 2007.

RAHMAN, S.H.; KHANAM D.; ADYEL T.M.; ISLAM M.S.; AHSAN M.A.; AKBOR M.A. Assessment of Heavy Metal Contamination of Agricultural Soil around Dhaka Export Processing Zone (DEPZ), Bangladesh: Implication of Seasonal Variation and Indices. Applied Sciences, v. 2, n. 3, p. 584-601, 2012.

RAMALHO, J.F.G.P.; SOBRINHO, N.M.B.A.; VELLOSO, A.C.X.; Contaminação da microbacia de Caetés com metais pesados pelo uso de agroquímicos. Pesquisa Agropecuária Brasileira, v. 35, n. 7, p. 1289-1303,2000.

SANTOS, S.F.A. Sinais de consciência. Os desafios da realidade contemporânea na construção da paisagem. Lisboa, 2010, 60p. Tese (Mestrado em Arquitectura Paisagista), Instituto Superior de Agronomia de Lisboa.

SANTOS, C. \& SÁ, N. Contaminação das águas subterrâneas pelo uso de pesticidas e adubos nas Terras da Costa. Lisboa, 2001. P. (Relatório de estágio), Instituto Conservação da Natureza, Paisagem Protegida Arriba Fóssil Costa Caparica.

SCU - Science Communication Unit. Science for Environment Policy, In-depth Report. Soil Contamination: Impacts on Human Health. Report produced for the European Commission DG Environment. Bristol: University of the West of England; 2013 [acesso em 13 março 2015]. Disp. em: http://ec.europa.eu/environment/integration/research/newsaler t/pdf/IR5_en.pdf.

SOWANA, A.; SHRESTHA, R.P.; PARKPIAN, P.; PONGQUAN, S. Influence of Coastal Land Use on Soil Heavy-Metal Contamination in Pattani Bay, Thailand. Journal of Coastal Research, v. 27 (Issue 2), p. 252-262, 2011.
TILLER, K.G. Heavy metals in soils and their environmental significance. Advances in Soil Science, v. 9, p. 113-114, 1989.

TOMÁŠ, J.; ÁRVAY, J.; TÓTH, T. Heavy metals in productive parts of agricultural plants. The Journal of Microbiology Biotechnology and Food Science, v. 1 (Special issue), p. 819-827, 2012.

US Salinity Laboratory: Diagnosis and improvement of saline and alkali soils. Agricultural Hand book, USDA, n. 60, 160p, 1954.

VAN PUT, A.; VAN GRIEKEN, R.; WILKEN, R.D; HUDEC, B. Geochemical characterization of suspended matter and sediment samples from the Elbe river by EPXMA. Water Research, v. 28, p. 643-655, 1994.

WANG, X.L.; SATO, T.; XING, B.S.; TAO, S. Health risks of heavy metals to the general public in Tianjin, China via consumption of vegetables and fish. Science of the Total Environment, v. 350, (Issue 1-3), p. 28-37, 2005.

WANG, L.; COLES, N.A.; CHUNFA, W; JIAPING, W. Spatial variability of heavy metals in the coastal soils under long-term reclamation. Estuarine, Coastal and Shelf Science, v. 151, p. 310-317, 2014.

WUANA R.A. \& OKIEIMEN F.E. Heavy Metals in Contaminated Soils: A Review of Sources, Chemistry, Risks and Best Available Strategies for Remediation. International Scholarly Research Network, ISRN Ecology, v. 2011, 20 p., 2011.

YUAN, L.; HAIBO, Z.; XIAOBING, C.; CHEN, T.; YONGMING, L.; PETER, C. Distribution of heavy metals in soils of the Yellow River Delta: concentrations in different soil horizons and source identification. Journal of Soils and Sediments, v. 14, n. 6, p. 1158-1168, 2014.

ZOVKO, M. \& ROMIC, M. Soil Contamination by trace metals: Geochemical Behaviour as an element of risk assessment. In: IMRAN AHMAD, D (Ed.). Earth and Environmental Sciences. InTech, p. 437-456, 2011.

Submetido em 16 de fevereiro de 2016 Aceito em 13 de março de 2018 